\title{
РАЗВИТИЕ ТЕОРИИ ИНВЕСТИЦИЙ В ПРОЦЕССЕ ТРАНСФОРМАЦИИ СОЦИАЛЬНО-ЭКОНОМИЧЕСКОЙ СИСТЕМЫ
}

\author{
(c) 2019 Ляченков Юрий Николаевич \\ соискатель кафедры экономической теории \\ Самарский государственный экономический университет, России, Самара \\ (c) 2019 Коновалова Мария Евгеньевна \\ доктор экономических наук, заведующий кафедрой экономической теории \\ Самарский государственный экономический университет, Россия, Самара \\ E-mail:mkonoval@mail.ru
}

В статье рассматриваются особенности эволюции теории инвестиции, обусловленной сменой индустриального способа производства постиндустриальным, основанного на масштабном применении информационных, цифровых технологий. Авторами доказывается необходимость пересмотра традиционных научных представлений относительно алгоритма осуществления инвестиционного процесса, его субъекта, объекта и форм реализации дохода. В статье обосновывается тот факт, что в теории информационной экономики основное внимание уделяется механизму принятия инвестиционного решения, мотивации хозяйствующих субъектов, что существенным образом трансформирует классическое представление о видах экономической активности хозяйствующих субъектов.

Ключевые слова: инвестиции, инвестиционный процесс, хозяйствующие субъекты, объект инвестирования, форма реализации дохода, мотивация, инвестиционный портфель.

Проблемы инвестирования традиционно являются актуальными в научном сообществе, по-прежнему интересна дискуссия относительно содержания и форм данного процесса. И это не случайно, поскольку инвестиции представляют собой движущую силу экономической системы, определенный драйвер ее развития [1]. Следует заметить, что ученые экономисты, начиная от меркантилистов и заканчивая представителями ннституционализма достаточно подробно исследовали факторы, формирующие мотивацию хозяйствующих субъектов в осуществлении вложений денежных средств в различные проекты.

Научная категория инвестиционного процесса, так же как и многие другие понятия подвержена эволюционному развитию. Как нам представляется трансформация инвестиционного процесса как научной дефиниции обусловлена изменением способа производства, формирующего каркас всей социально-экономической системы [2]. Более детальное и пристальное изучение инвестиционного процесса особенно стало заметно в индустриальный период развития, хотя нельзя отрицать, что само инвестирование как явление наблюдалось и ранее, в аграрную эпоху. Тем не менее, следует подчеркнуть, что в доиндустриальный период инвестиционный процесс имел фрагментарный характер, и, как правило, представлял собой отдельный элемент воспроизводства трудовых ресурсов, сельскохозяйственного производства, осуществления работ по ведению домашнего хозяйства. Промышленная революция, экспоненциальный рост индустрии обусловил приоритет фактора капитала, что в конечном итоге привело к концентрации научных работ по проблемам инвестирования, его роли в социально-экономическом развитии и создании предпосылок для качественного экономического роста.

В современных условиях формирования нового способа производства на основе масштабной экспансии информационных технологий требуется пересмотр традиционных категорий инвестиционного процесса [3]. В текущий момент происходит, по сути, трансформация элементов, форм реализации, объектов инвестиционного процесса, что вызывает необходимость более углубленного его изучения не только с точки зрения теоретических аспектов, но и практических позиций.

Первоначально, представители меркантилистского направления экономической мысли, такие как Т. Мэн, Дж. Докк, Д. Юм, Ж.Б. Кольбер 
не акцентировали внимание на самом инвестиционном процессе в силу того, что он мог быть ими рассмотрен лишь в снятом виде, опосредованно через другие стороны системы общественного воспроизводства. Будучи сторонниками активного сальдо торгового баланса, они ратовали за положительную динамику притока денег с страну, что, как справедливо полагали данные ученые, создает необходимый запас финансовых ресурсов для осуществления инвестирования. особенностью меркатилизма как научного направления стало пристальное изучение сферы обращения, что в конечно итоге приводит их к пониманию того факта, что объектом инвестирования могут быть и спекулятивные операции, приносящие выгоду, в том числе за счет разницы в курсах валют. Несмотря на попытки более глубокого теоретического обоснования инвестиционного процесса, меркантилистам не удалось сформулировать ясный алгоритм инвестиционного процесса, начиная от его источников и заканчивая формой извлечения дохода.

Дальнейшее развитие теории инвестиций происходило в трудах представителей физиократии и классической школы политэкономии. В отличии от меркантилистов классики не считают источником инвестирования спекулятивные сделки, их внимание в основном сосредоточено на реальном процессе воспроизводства, основу которого составляет накопление капитала, a, значит, инвестиции в активную и пассивную части основных производственных фондов [4]. Достоинством представителей классической школы политэкономии является их целостный взгляд на построение социально-экономической системы, в том числе общественного воспроизводства. Являясь апологетами принципа эквивалентного обмена, они полагают невозможным получения дополнительного дохода посредством спекулятивных операций, поскольку выигрыш одних и потери других, по их мнению, не изменят общего равенства в системе общественного воспроизводства. Таким образом единственным источником инвестиционного дохода [5] является сфера производства, то есть вложения в основные производственные фонды и рабочую силу [6].

Дальнейшее развитие индустриального способа производства, появление новых форм организации промышленного производства неизбежно привело к сращиванию промышленного и финансового капиталов, что поста- вило под сомнение традиционные положения классической школы политэкономии, особенно ключевой принцип эквивалентности обмена. Так, например, в третьем томе «Капитала» К. Маркс рассуждает о причинах образования абсолютной ренты, справедливо полагает, что ее основой становится монополия на земельные ресурсы. То есть уже здесь, мы можем заметить, что К. Маркс отходит от условия эквивалентного обмена, поскольку несовершенная конкуренция, а именно, наличие монополии, априори противоречит такому базовому положению. Исследование Марксом таких категорий как ложной социальной стоимости, финансового капитала не совсем вписываются в концепцию трудовой теории стоимости. Он не отрицает того факта, что по мере развития финансового сектора, деньги начинают приобретать все большую суверенность, а значит, способны иметь самостоятельную ценность и выступать в качестве цели инвестирования.

Признание активной роли денег в качестве источника инвестирования имеет место в трудах представителей неоклассического направления экономической мысли. Его представители «реабилитируют» торговые отношения, полагая, что они могут обеспечивать взаимовыгодный обмен благами, который позволит сторонам, участвующим в сделке получить выигрыш за счет более высокой оценки приобретаемого блага по сравнению с ожидаемой ценностью. Так, Е. Бем Баверк полагал, что рыночная цена - это лишь некий ориентир, который может измениться в будущем, что заставляет индивидов постоянно пересматривать свои оценке и корректировать ожидания. Инвестиционный процесс, описанный в работах Е. Бем-Баверка, демонстрирует изменение представлений относительно его содержания и форм, сфере потребления отводится ключевая роль, в том числе и в вопросе поиска источников инвестирования [7]. Представители неоклассической школы убеждены, что капитал как категория запаса и инвестиции как потоковая переменная должны определяться не затратным методом, а с помощью оценки будущих доходов, что отмечается в трудах И. Фишера. В его работах уже четко прослеживается возрастание роли процента как ключевого дохода, превышение нормы дохода над рыночной процентной ставкой - вот основной стимул к инвестированию. Еще один представитель неоклассической школы, а именно А. Пигу уверен, что инвести- 
ционная активность экономических агентов зависит от количества денег, находящихся в обращении. Оппонируя Фишеру, делающему акцент на денежном предложении, А. Пигу рассуждает о спросе на деньги, как основном факторе равновесия, что делает его теорию более релевантной демонстрируемому поведению хозяйствующих субъектов в процессе осуществления инвестиций и сбережений.

Принципиально иные взгляды на процесс инвестирования отражаются в трудах Дж.М. Кейнса [8]. Характерной чертой его исследования является четко выраженный макроэкономический подход за счет использования соответствующего инструментария, методов агрегирования и экономико-математического моделирования, которые он распространяет не только на количественные параметры, но и на поведенческие особенности хозяйствующих субъектов. Согласно концепции Кейнса, в экономике присутствуют четыре типа экономических агентов: домашние хозяйства, фирмы, государство и сектор заграница, которые имеют четко выраженный функционал, отражающий реализацию принципа равенства потока доходов и расходов. В закрытой экономики равновесие сбережений и инвестиций обеспечивается совпадением планом двух агрегированных субъектов - домохозяйств и фирм. Не отрицая неоклассического постулата равновесности, Дж. Кейнс делает вывод о том, что совпадение инвестиций и сбережений является, скорее, частным случаем или исключением из правил. Основная критика Кейнса связана с тем, что, по его мнению, далеко не все сбережения превращаются в инвестиции, поскольку домашние хозяйства и фирмы имеют различную мотивацию. В кейнсианской теории анализу сберегательного и инвестиционного поведения уделяется значительное внимание, делается вывод о ключевой роли экономического поведения субъектов в процессе принятия инвестиционных решений.

Монетарная школа экономической мысли также уделяла доставочное внимание исследованию инвестиционного процесса, но уже с учетом воздействия на него колебаний денежной массы. Как полагает М. Фридмен циклические колебания денежного рынка изменяют денежную оценку будущих инвестиций, что говорит о преимуществе вложений в долгосрочном периоде, когда будут нивелированы дисбалансы рынка денег. По сути, идеи монетаризма повторяют основные постулаты неоклассического анализа, однако, выводят теорию инвестиций на новый качественный уровень. Монетаристы настаивают на более детальном и глубоком изучении мотивов, побуждающих осуществлять экономических агентов инвестиции. В условиях экспансии денежной сферы идеи монетаристского направления получили значительную популярность.

Конец XX века ознаменовался в экономической науке постепенным отходом от принципа рациональности поведения хозяйственных акторов, а также равновесности экономической системы. В этот период в исследовании инвестиционного процесса все большее внимание уделяется изучению причин, побуждающих инвестировать, объектам инвестирования и формам реализации дохода. В отличие от индустриальной эпохи, в которой традиционными объектами инвестирования являлись активная и пассивная формы производственных фондов, изменения в объемах товарно-материальных запасов, в условиях формирования информационной экономики основными объектами инвестиционных вложений становятся нематериальные активы, такие как ценные бумаги, права на интеллектуальную собственность, конструированные финансовые продукты. Становление и распространение новой информационной стадии развития общества увеличивает интерес исследователей к проблемам информации, аккумулированию знаний, формированию человеческого и интеллектуального каптала, что в конечном итоге способствует пересмотру традиционных научных взглядов на инвестиционный процесс.

Апологеты теории информационной экономики, к которым можно отнести представителей посткейнсианства, неолиберализма и новой институциональной школы акцентируют внимание не столько на изучении реальных капиталовложений, источниках инвестирования, стадий инвестиционного процесса, сколько анализируется инвестиционное поведение хозяйствующих субъектов, как потенциальных субъектов инвестирования [9]. 


\section{Библиографический список}

1. Петров Н.А., Михайлов А.М. Воздействие прямых инвестиций на развитие национальных экономик. АНАЛИЗ, КОНЦЕПЦИИ, МЕТОДЫ /Saarbrucken (Германия). С. 16

2. Михайлов А.М. Эволюция и взаимодействие факторов производства в процессе смены технологических способов производства //Экономические науки. 2016. № 135. С. 19-22.

3. Михайлов А.М., Карова Е.В. Ключевые аспекты трансформации производства индустриального типа в инновационное //Вестник Самарского государственного экономического университета. 2014. № 3 (113). С. 54-60.

4. Кенэ, Ф., Тюрго, А.Р.Ж., Дюмон де Немур, П.С. Физиократы. Избранные экономические произведения / Под ред. П.Н. Клюкина - М.: Эксмо, 2008. С. 34-36.

5. узьмина О.Ю., Михайлов А.М. Экономическая природа факторных доходов //Экономические науки. 2014. № 115. С. 89-93.

6. Маркс, К. Капитал. Критика политической экономии. Т.1 / М.: Политиздат. 1963.- С. 174.

7. Бем-Бавер, О. Избранные труды о ценности, проценте и капитале / - М.: ООО Изд-во ЭКСМО, 2009. С. 76-78.

8. Кейнс, Дж. М. Общая теория занятости, процента и денег / Пер. с англ.- М.: Прогресс, 1978.- С. 281.

9. Simon, H. Rational decision - making in business organizations// Les. Prih Nobel. 1978- Stockholm,1979. P285. 